\title{
Effect of Addition of Dexamethasone to Ropivacaine in Supraclavicular brachial plexus block.
}

\author{
Dr. Feroz Ahmad Dar ${ }^{1}$ (M.D), Dr. Neelofar Jan ${ }^{2}$ (M.B.B.S) \\ ${ }^{I}$ Department of Anaesthesiology and Critical care, SKIMS, Medical College and Hospital, Srinagar, India. \\ ${ }^{2}$ Resident (M.B.B.S), Department of Medicine, SKIMS, Soura, Srinagar, India,
}

\begin{abstract}
Background and Objectives: We evaluated the effect of adding dexamethasone to ropivacaine for supraclavicular brachial plexus blockade. The primary endpoints were the onset and total duration of sensory and motor block, quality of analgesia and duration of analgesia.

Methods: Eighty patients of age group 20-50 years, scheduled for various elective orthopaedic surgeries on forearm and around the elbow under supraclavicular brachial block were divided into 2 equal groups in a randomized, double-blinded fashion. In group $R(n=40), 30 \mathrm{ml}(150 \mathrm{mg})$ of $0.5 \%$ ropivacaine $+2 \mathrm{ml}$ saline and in group $R D(n=40), 30 \mathrm{ml}(150 \mathrm{mg})$ of $0.5 \%$ ropivacaine $+2 \mathrm{ml}$ dexamethasone (8mg) were given. Motor and sensory block onset times, block durations, quality of intraoperative analgesia and duration of analgesia were recorded.

Results: Demographic data and surgical characteristics were similar in both groups. The sensory and motor block onset time was earlier in group $R D$ as compared to group $R(P<0.05)$. Sensory and motor blockade duration were longer in group $R D$ than in group $R(P<0.001)$. Duration of analgesia was longer in group $R D$ than in group $R(P<0.001)$. The 24 hour Visual Analog Scale was more in group $R$ as compared to group $R D$. The quality of anaesthesia was excellent in both the groups. Mean arterial blood pressure levels in groups at 5 , $10,15,30,45,60,90,120$ and 150 minutes were statistically insignificant between the two groups $(P>0.05)$. The mean pulse rate at different time intervals were statistically insignificant between the groups $(P>0.05)$.

Conclusions: Dexamethasone added to ropivacaine for supraclavicular brachial plexus block prolongs the duration of the block and the duration of postoperative analgesia.
\end{abstract}

Keywords: Dexamethasone, Ropivacaine, Supraclavicular Brachial Plexus Block

\section{Introduction}

Ropivacaine is structurally closely related to bupivacaine. Compared to racemic bupivacaine, ropivacaine has lower central nervous system toxicity and cardiotoxicity ${ }^{(1-3)}$, and it is better tolerated than bupivacaine ${ }^{(4,5)}$. Based on its profile, ropivacaine may be preferable to bupivacaine. Controversy exists regarding the potency of ropivacaine : in some areas it is clearly less potent, whereas in other areas this is less obvious. However ropivacaine alone provide analgesia for not more than 4-8 hours in peripheral nerve blocks. Increasing the duration of local anaesthetic action is often desirable because it prolongs surgical anaesthesia and analgesia. Different additives have been used to prolong regional blockade. Additives like opioids, clonidine, verapamil etc were added to local anaesthetics, but the results are either inconclusive or associated with side effects ${ }^{(6-8)}$. Steroids have powerful anti-inflammatory as well as analgesic property. Perineural injection of steroids is reported to influence post operative analgesia. Dexamethasone microspheres have been found to prolong the block duration in animal and human studies and adding methyl prednisolone to local anaesthetic increases the duration of axillary brachial block ${ }^{(9-12)}$. With this background, this study was carried out to evaluate the efficacy of dexamethasone as an adjuvant to ropivacaine in supraclavicular brachial block. Dexamethasone with ropivacaine use in axillary blocks has not been described. In this study, we investigated the effect of adding dexamethasone to ropivacaine for supraclavicular brachial plexus blocks. Our primary endpoints were the onset time, duration of motor and sensory blocks, and quality of intraoperative analgesia.

\section{Methods}

After ethical committee approval and informed consent, 80 ASA physical grades I-II patients of either sex, aged 20-50 years scheduled for elective orthopaedic surgeries of upper limb under supraclavicular brachial plexus block were included in this study. Patients were not premedicated before the block. After insertion of a 20 -gauge IV cannula in the nonoperated arm, a $5 \mathrm{ml} / \mathrm{kg} / \mathrm{h}$ infusion of $0.9 \% \mathrm{NaCl}$ solution was started. After standard anaesthesia monitoring, baseline measurements of heart rate (HR), non-invasive arterial blood pressure, peripheral oxygen saturation (Spo2), and respiratory rate were recorded before the block was performed. After appropriate patient positioning and strict aseptic and antiseptic precautions midclavicular point, external jugular vein and subclavian artery pulsation were identified. About $2 \mathrm{~cm}$ above the midclavicular point just lateral to subclavian artery pulsation, a 24 gauge 1.5 inch needle was introduced and directed caudal and medially until 
paraesthesia was encountered, when local anaesthetics with or without dexamethasone was injected in this area. Patients were randomly allocated using a sealed envelope technique to receive either $30 \mathrm{ml}$ of $0.5 \%$ ropivacaine with $2 \mathrm{ml}$ of isotonic sodium chloride solution (group $\mathrm{R}, \mathrm{n}=40$ ), or $30 \mathrm{ml}$ of $0.5 \%$ ropivacaine with $2 \mathrm{ml}(8 \mathrm{mg}$ ) of dexamethasone (group $\mathrm{RD}, \mathrm{n}=40$ ) in a double-blind fashion. The drug solutions were prepared by an anaesthesiologist not involved in the study. Sensory block was assessed by pinprick test using a 3-point scale: 0 $=$ normal sensation, 1 = loss of sensation of pinprick (analgesia), $2=$ loss of sensation of touch anesthesia). Motor block was evaluated by Modified Bromage Scale (4=Full power in relevant muscle group, $3=$ Reduced power but ability to move muscle group against resistance, $2=$ Ability to move relevant muscle group against gravity but inability to move against resistance, $1=$ Flicker of movement in relevant muscle group, $0=$ No movement in relevant group). Sensory and motor blocks were evaluated every 3 minutes up to 30 minutes after injection, and then every 30 minutes after surgery, until they had resolved. Sensory onset time was defined as the time interval between the end of total local anesthetic administration and complete sensory block (score 2). Duration of sensory block was defined as the time interval between the end of local anaesthetic administration and the complete resolution of sensory block (normal sensation or score 0). Motor block was defined as no movement in relevant group (Modified Bromage Scale 0). Duration of motor block was defined as the time interval between the end of local anaesthetic administration and the recovery of full power in relevant muscle group (Modified Bromage Scale 4). The quality of intraoperative analgesia was judged by the investigator at the end of surgery as excellent (no discomfort or pain), good (mild pain or discomfort, no need for additional analgesics), fair (pain that required additional analgesics), or poor (moderate or severe pain that needed more than fentanyl $100 \mu \mathrm{g}$ or general anaesthesia). HR, systolic arterial blood pressure (SAP), and diastolic arterial blood pressure (DAP) were recorded at 0 minutes, 5 minutes, 10 minutes, 15 minutes, 30 minutes, 45 minutes, 60 minutes, 90 minutes, 120 minutes and 150 minutes. Adverse events comprised hypotension (a 20\% decrease in relation to the baseline value), bradycardia ( $\mathrm{HR}<50$ beats per minute), hypoxemia $\left(\mathrm{SpO}_{2}<90 \%\right)$, or nausea and vomiting. Pain was assessed using the Visual Analog Scale (0-10) every 60 minutes during first 24 hours. Nursing staff administered IM diclofenac 75mg when the Visual Analog Scale $>4$. The time between the end of local anesthetic administration and the first analgesic request was recorded as the duration of the analgesia. Data were entered and analyzed with the Graph Pad.com (version 5, 2010). Statistical tests used for comparison is unpaired t-test and fisher's exact test. Results are presented as mean (SD) and number (\%) of cases as appropriate. The level of significance was set at $\mathrm{P}<0.05$, and $95 \%$ confidence intervals were calculated for the main outcome measures.

\section{Results}

The demographic data and surgical characteristics were similar in each group (Table 1).

\begin{tabular}{|c|c|c|c|}
\hline & Group R & Group DR & $P$ value \\
\hline Age (years) & $30 \pm 8$ & $31 \pm 9$ & 0.6009 \\
\hline $\operatorname{Sex}(M / F)$ & $34 / 6$ & $35 / 5$ & 1.0000 \\
\hline Weight (kg) & $68 \pm 10$ & $65 \pm 12$ & 0.2282 \\
\hline Height (cm) & $172 \pm 6$ & $174 \pm 8$ & 0.2097 \\
\hline Surgical duration (min) & $93 \pm 36$ & $98 \pm 42$ & 0.5692 \\
\hline BMI $\left(\mathrm{kg} / \mathrm{m}^{2}\right)$ & $22.7 \pm 3.1$ & $23.6 \pm 4.0$ & 0.2641 \\
\hline
\end{tabular}

Sensory and motor block onset time was earlier in group $\mathrm{RD}$ as compared group $\mathrm{R}$ (Table 2; $\mathrm{P}<0.05$ ). Sensory and motor blockade durations were longer in group $\mathrm{RD}$ than in group $\mathrm{R}$ (Figure $1 ; \mathrm{P}<0.001$ ).

\begin{tabular}{|l|l|l|l|}
\hline Table 2: Comparison of quality of block in two groups & Group R & Group RD & P value \\
\hline & $17.5 \pm 4.2$ & $14.65 \pm 3.31$ & 0.0124 \\
\hline Onset time of sensory block (min) & $20.67 \pm 3.03$ & $18.01 \pm 4.51$ & 0.0210 \\
\hline Onset time of motor block (min) & $7.5 . \pm 0.55$ & $12.3 \pm 0.40$ & $<0.0001$ \\
\hline Total duration of sensory block (hr) & $6.4 \pm 0.30$ & $8.2 \pm 0.50$ & $<0.0001$ \\
\hline Total duration of motor block (hr) & \multicolumn{3}{|l}{} \\
\hline Values are expressed as mean \pm SD
\end{tabular}

Duration of analgesia was significantly longer in group $\mathrm{RD}$ than in group $\mathrm{R}$ (Table 3 ; $\mathrm{P}<0.001$ ). The intraoperative quality of analgesia was excellent and similar in both groups (Table 3). However two patients in 
group $\mathrm{R}$ and one patient in group $\mathrm{RD}$ complain mild pain and discomfort but no additional analgesic required. It was statistically insignificant between the two groups ( $\mathrm{p}$ value $>0.05$ ). None of the patients in both the groups had poor quality of analgesia (Table 3).

\begin{tabular}{|l|l|l|l|}
\hline Table 3: Quality of analgesia in two groups & Group R & Group RD & P value \\
\hline & 38 & 37 & \\
\hline Excellent & 2 & 2 & $>0.05$ \\
Good & 0 & 1 & \\
Fair & 0 & 0 & $<0.0001$ \\
Poor & $8.30 \pm 0.40$ & $14.50 \pm 0.30$ & 0.0115 \\
\hline Time to First analgesic request (hr) & $30(75 \%)$ & $18(45 \%)$ & \\
\hline Postoperative analgesic consumption during the first 24 hours [n (\%)] & & \\
\hline Values are expressed as mean \pm SD , numbers or percentage (\%) &
\end{tabular}

From the sixth hour, patients who received dexamethasone showed a significantly lower VAS than the patients received ropivacaine only (Figure 2). Mean arterial pressure and mean pulse rate in group R and group RD at $0,5,10,15,30,45,60,90,120$ and 150 minutes were statistically insignificant $(P>0.05)$. No side effects including nausea, vomiting, hypotension, and hypoxemia were reported in either group.
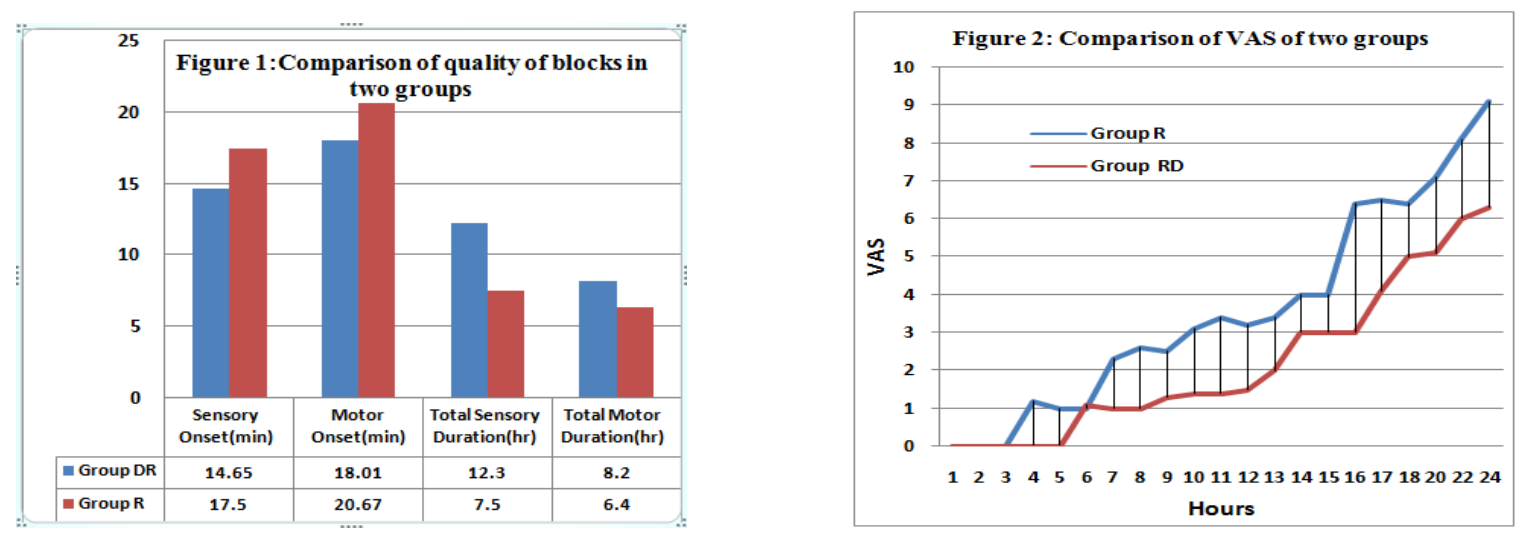

\section{Discussion}

In this study, we demonstrated that in patients undergoing supraclavicular brachial plexus block, dexamethasone added to ropivacaine, shortens sensory and motor block onset time and extends block durations. Brachial plexus block is an easy and relatively safe procedure for upper limb surgeries. Ropivacaine provided better operating conditions but the duration of analgesia is rarely maintained for more than 4-8 hours. Addition of steroid to local anaesthetics effectively and significantly prolongs the duration of analgesia as well as producing earlier onset of action ${ }^{(13)}$. Steroids are very potent anti-inflammatory and immunosuppressive agents. Perineural injection of steroid is reported to influence postoperative analgesia. Epidural steroids were used for treatment of back pain and sciatica ${ }^{(14)}$. Various steroids has been used for this purpose, but dexamethasone, a derivative synthetic glucocorticoid is preferred because of its highly potent anti-inflammatory property, about 25-30 times as potent as hydrocortisone and without any mineralocorticoid activity. Thus was found to be safer and devoid of potential side effects. Pre-operative administration of dexamethasone by oral and intravenous routes has been shown to reduce overall pain scores and analgesic requirements in the postoperative period without any adverse effects in various oral and general surgical procedures ${ }^{(15)}$. Dexamethasone is also known to reduce post-operative nausea and vomiting. The possible mechanism of analgesic and antiemetic actions are due to anti-inflammatory property of dexamethasone $\mathrm{e}^{(16,17)}$.

In reported study significantly early onset of sensory and motor block was noticed in group DR compared to group R $(p<0.05)$. The early onset of action might be due to synergistic action of dexamethasone with local anaesthetics on blockage of nerve fibres. The duration of pain relief (postoperative analgesia) was markedly prolonged in group $\mathrm{RD}(14.5 \pm 0.3$ hours), while it was only $8.3 \pm 0.4$ hours in group $\mathrm{R}(\mathrm{p}<0.001)$. A variety of animal studies have reported the analgesic effect of corticosteroids by adding to local anaesthetics for peripheral nerve blockade. Droger and colleagues have shown that dexamethasone incorporation into bupivacaine caused prolongation of the intercostals nerve blockade in sheep ${ }^{(18)}$. Castillo and co-workers reported that addition of 
dexamethasone to bupivacaine resulted in prolongation of sciatic nerve blockade in rats ${ }^{(19)}$. These studies have attributed the prolongation of the block duration to the anti-inflammatory effect of steroids. In one study on human volunteers, addition of dexamethasone to bupivacaine microcapsules provided prolongation of the intercostals nerve blockade ${ }^{(20)}$. Use of oral dexamethasone succeeded in reducing pain and swelling following tooth extraction ${ }^{(21)}$. Addition of dexamethasone to lidocaine ${ }^{(22)} 1.5 \%$ solution for axillary brachial plexus block resulted in longer sensory and motor blockade duration (sensory blockade duration was $242 \pm 76$ vs. $98 \pm 33$ min for control and motor blockade duration was $310 \pm 81$ vs. $130 \pm 31 \mathrm{~min}$ for control). In another study, 40mg methyl prednisolone was added to a mixture of local anaesthetic formed of $20 \mathrm{ml}$ bupivacaine $+20 \mathrm{ml}$ mepivacaine $+0.2 \mathrm{ml}$ epinephrine for axillary brachial plexus block ${ }^{(23)}$. It resulted in longer analgesia (23 vs. 16 $\mathrm{h}$ for control) and longer motor blockade duration (19 vs. $13 \mathrm{~h}$ for control). Shrestha and co-workers ${ }^{(24)}$ added 8 $\mathrm{mg}$ of dexamethasone to a mixture of lidocaine and bupivacaine for supraclavicular brachial plexus block. Dexamethasone provided a faster onset of action and longer duration of analgesia without any adverse effects. Parrington and colleagues ${ }^{(25)}$ added $8 \mathrm{mg}$ of dexamethasone to $30 \mathrm{ml}$ mepivacaine $1.5 \%$ during supraclavicular brachial plexus blockade. The dexamethasone group showed a longer duration of analgesia: 332 (225-448 min) vs. $228(207-263 \mathrm{~min}) \mathrm{min}$ in the control group, whereas the onset times of sensory and motor blockade were similar in both groups. In another study ${ }^{(26)}$, Cummings III and co-workers reported longer analgesia when using ropivacaine or bupivacaine for interscalene blocks, with the effect being more potent with ropivacaine. However, the block duration was more prolonged with bupivacaine than with ropivacaine.

\section{Conclusion}

Addition of dexamethasone to ropivacaine in supraclavicular brachial plexus block significantly prolongs the duration of analgesia and motor block in patients undergoing upper limb surgeries and is a remarkably safe and cost effective method of providing post operative analgesia.

\section{References}

[1]. Reiz S., Häggmark S., Johansson G., Nath S.,V Cardiotoxicity of ropivacaine - a new amide local anaesthetic agent, Acta anaesthesiol. scand., 33, 93-98, 1989.

[2]. Pitkänen M., Feldman H. S., Arthur G. R., Covino B. G., Chronotropic and inotropic effects of ropivacaine, bupivacaine and lidocaine in the spontaneously beating and electrically paced isolated, perfused rabbit heart, Reg. Anesth., 17, 183-192, 1992.

[3]. Sztark F., Malgat M., Dabadie P., Mazat J. P., Comparison of the effects of bupivacaine and ropivacaine on heart cell mitochondrial bioenergetics, Anesthesiology, 88, 1340-1349, 1998.

[4]. Scott D. B., Lee A., Fagan D., Bowler G. M. R., Bloomfield P., Lundh R., Acute toxicity of ropivacaine compared with that of bupivacaine, Anesth. Analg., 69, 563-569, 1989.

[5]. Knudsen K., Beckman-Suurkula M., Blomberg S., Sjovall J., Edvardsson N., Central nervous and cardiovascular effects of i.v. infusions of ropivacaine, bupivacaine and placebo in volunteers, British Journal of Anaesthesia, 78, 507-514, 1997.

[6]. Wakhlo R, Gupta V, Raina A, Gupta SD, Lahori VU. Supraclavicular Plexus Block: Effect of Adding Tramadol or Butorphanol as an Adjuncts to Local Anaesthetic on Motor and Sensory Block and Duration of Post-operative Analgesia. J Anaesth Clin Pharmacol $2009 ; 25(1): 17-20$.

[7]. Gabriella I, Adnane M, Desire-Pascal D, et.al. The effects of clonidine added to mepivacaine for paronychia surgery under axillary brachial plexus block. Anesth Analg 2005; 100(4):1179-1183.

[8]. Lalla RL, Anant S, Nanda HS. Verapamil as an Adjunct to Local Anaesthetic for Brachial Plexus Blocks. MJAFI 2010; 66 : $22-24$.

[9]. Castillo J, Curley J, Hotz J, et al. Glucocorticoids prolong rat sciatic nerve blockade in vivo from bupivacaine microspheres. Anesthesiology 1996; 85:1157-66.

[10]. Droger C, Benziger D, Gao F, Berde CB. Prolonged intercostals nerve blockade in sheep using controlled-release of bupivacaine and dexamethasone from polymer microspheres. Anesthesiology 1998; 89: 969-74.

[11]. Kopacz DJ, Lacouture PG, Wu D, et al. The dose response and effects of dexamethasone on bupivacaine microcapsules for intercostals blockade (T9 to T11) in healthy volunteers. Anesth Analg 2003; 96: 576-82.

[12]. Stan T, Goodman E, Cardida B, Curtis RH. Adding methylprednisolone to local anesthetic increases the duration of axillary block. Reg Anesth Pain Med 2004; 29: 380-382.

[13]. Golwala MP, Swadia VN, Dhimar AA, Sridhar NV. Pain Relief by Dexamethasone as an Adjuvant to Local Anaesthetics in Supraclavicular Brachial Plexus Block. J Anaesth Clin Pharmacol 2009; 25(3): 285-288

[14]. Benzon HT. Epidural steroids. In: Raj PP, editor. Pain medicine, a comprehensive review. UK: Mosby Publications; 1999. P.259263.

[15]. Elhakim M, Ali NM, Rashed. Dexamethasone reduces postoperative vomiting and pain after paediatric tonsillectomy. Can.J Anaesth 2003; 50; 392-97.

[16]. Bisgaard T, Klarskov B. Pre-operative dexamethasone improves surgical outcome after laproscopic cholecystectomy. A randomized double blind placebo controlled trial. Ann Surg 2003; 238; 651-60.

[17]. Liu K, Hsu CC, Chia YY. Effect of dexamethasone on postoperative pain and emesis. Br J Anaesth 1998; 80; 85-86.

[18]. Droger C, Benziger D, Gao F, Berde CB. Prolonged intercostals nerve blockade in sheep using controlled-release of bupivacaine and dexamethasone from polymer microspheres.Anesthesiolog, 1998; 89:969-74.

[19]. Castillo J, Curley J, Hotz J, Uezono M, Tigner J, Chasin M, et al. Glucocorticoids prolong rat sciatic nerve blockade in vivo from bupivacaine microspheres. Anesthesiology 1996; 85:1157-66.

[20]. Kopacz DJ, Lacouture PG, Wu D, Nandy P, Swanton R, Landau C. The dose response and effects of dexamethasone on bupivacaine microcapsules for intercostals blockade (T9 to T11)in healthy volunteers. Anesth Analg 2003;96:576-82

[21]. Baxendale BR, Vater M, Lavery KM. Dexamethasone reduces pain and swelling following extraction of third molar teeth. Anaesthesia 1993; 48:961-4.

[22]. Movafegh A, Razazian M, Hajimaohamadi F, Meysamie A. Dexamethasone added to lidocaine prolongs axillary brachial plexus blockade. Anesth Analg 2006;102:263-7. 
[23]. StanT, Goodman E, Cardida B, Curtis RH.Adding methylprednisolone to local anesthetic increases the duration of axillary block. Reg Anesth Pain Med2004;29:380-1

[24]. Shrestha BR, Maharjan SK, Tabedar S. Supraclavicular brachial plexus block with and without dexamethasone - A comparative study. Kathmandu Univ Med J (KUMJ) 2003; 3:158-60.

[25]. Parrington SJ, O'Donnell D, Chan VW, Brown-Shreves D, Subramanyam R, Qu M, et al. Dexamethasone added to mepivacaine prolongs the duration of analgesia after upraclavicular brachial plexus blockade. Reg Anesth Pain Med 2010; 35:422-6.

[26]. Cummings KC III, Napierkowski DE, Parra-Sanchez I, Kurz A, Dalton JE, Brems JJ, et al. Effect of dexamethasone on the duration of interscalene nerve blocks with ropivacaine or bupivacaine. Br J Anaesth 2011; 107:446-53. 